\title{
Research Article \\ Effects of Asphalt Mix Design Properties on Pavement Performance: A Mechanistic Approach
}

\author{
Ahmad M. Abu Abdo' ${ }^{1}$ and S. J. Jung ${ }^{2}$ \\ ${ }^{1}$ Department of Civil \& Infrastructure Engineering, American University of Ras Al Khaimah, P.O. Box 10021, Ras Al Khaimah, UAE \\ ${ }^{2}$ Department of Civil Engineering, University of Idaho, P.O. Box 441022, Moscow, ID 83844-1022, USA \\ Correspondence should be addressed to Ahmad M. Abu Abdo; ahmed.abuabdo@aurak.ac.ae
}

Received 29 April 2016; Accepted 4 July 2016

Academic Editor: Luigi Di Sarno

Copyright (c) 2016 A. M. Abu Abdo and S. J. Jung. This is an open access article distributed under the Creative Commons Attribution License, which permits unrestricted use, distribution, and reproduction in any medium, provided the original work is properly cited.

\begin{abstract}
The main objective of this study was to investigate the effects of hot mix asphalt material properties on the performance of flexible pavements via mechanistic approach. 3D Move Analysis software was utilized to determine rutting and cracking distresses in an asphalt concrete (AC) layer. Fourteen different Superpave mixes were evaluated by utilizing results of the Dynamic Modulus ( $\left.\left|E^{*}\right|\right)$ Test and the Dynamic Shear Modulus $\left(\left|G^{*}\right|\right)$ Test. Results showed that with the increase of binder content, the tendency of rutting in AC layer increased. However, with the increase of binder content, the cracking of AC layer lessened. Furthermore, when different binder grades were evaluated, results showed that with the increase of the upper binder grade number, rutting decreased, and with the increase of the lower binder grade number, rutting increased. Furthermore, analysis showed that with the increase of the lower binder grade number, higher percent of bottom up cracks would result. As a result of the analysis, binder grade should not be solely considered for cracking in AC layer; binder content and aggregate structure play a big role. Finally, results illustrated that the mechanistic approach is a better tool to determine the performance of asphalt pavement than commonly used methods.
\end{abstract}

\section{Introduction}

Most of pavement industry and highway agencies adopted the American Association of State Highway Transportation Officials (AASHTO) Design Guide as the primary design method for flexible pavement structure. As of now, most are using the 1993 version of the AASHTO Pavement Design Guide. While it served well for several decades, many serious fallbacks exist for this design method. It was based on empirical models developed from the AASHO Road Test back in the 1950s [1]. This method did not account for the complex material properties of asphalt mixes, especially their viscous behavior and load frequency and rate dependency.

In recognition of the limitations of the earlier guide, AASHTO is developing an improved design guide. This work was conducted under two major research projects, National Cooperative Highway Research Program (NCHRP) Projects 1-37A and 1-40. The end products of these research efforts were the development of a mechanistic-empirical pavement design guide (MEPDG) and the accompanying software [2, 3]. By the end of 2007, the MEPDG was adopted as an Interim AASHTO design standard [4]. However, there are still few issues with full implementation of the new design method. Since it is still under evaluation, developers of the new guide recommended against using it without verification, validation, and, if needed, calibration by comparing actual pavement performance data, which are locally obtained, against results obtained by the new guide [5].

Furthermore, the Strategic Highway Research Program (SHRP) developed a new binder classification system and design of asphalt mixes Superpave (Superior Performing Asphalt Pavements) and it was introduced in early 1990s $[6,7]$. The main goal of this new design was to lower maintenance costs by extending the life of flexible pavements and to reduce premature failures. SHRP targeted three main distresses: rutting, fatigue cracking, and thermal cracking. It was argued that by choosing the correct Superpave binder grade with the right aggregate structure these distresses would be minimized. 
Based on the above, many studies were conducted to investigate the influence of asphalt mixes properties (e.g., aggregate sources and structures and binder contents and grades) on the performance of asphalt mixes. Elseifi et al. [8] evaluated different asphalt mixes performance by characterizing asphalt mixes' viscoelastic properties at intermediate and high temperatures using three-dimensional finite element (FE) model to accurately simulate pavement responses under different load and temperature conditions. Results of the developed FE model were compared against fieldmeasured pavement responses from the Virginia Smart Road. Results showed that viscoelastic model was correlated well with field measurements. Bayomy et al. [9] evaluated thirtyfour asphalt mixes. The study showed that fracture resistance of asphalt mixes measured by fracture resistance parameter $\left(J_{c}\right)$ is highly sensitive to asphalt binder grades and contents and aggregate structures. Abu Abdo et al. [10] evaluated rutting tendency of asphalt mixes by testing 11 different mixes. These tests included Dynamic Modulus $\left(\left|E^{*}\right|\right)$, Flow Number (FN), and the Asphalt Pavement Analyzer (APA) tests. In a later study [11], 21 different asphalt mixes were evaluated to determine the effect of asphalt material properties on fatigue cracking of asphalt mixes. Binder grades and contents and different aggregate structures were used to develop the mixes in both studies. Results showed that asphalt mixes properties played a huge role in the performance of asphalt mixes.

Esfandiarpour et al. [12] conducted multiple tests to assess the effects of asphalt mix properties, collected from different project sites in Manitoba, on MEPDG outputs. Their findings were anticipated to assist agencies to determine the feasibility of advanced testing and their effects on flexible pavement predicted distresses. Ahmad et al. [13] conducted a study to compare rutting and dynamic modulus of different Superpave and Marshall mixes. They argued that Superpave mix design showed better performance when compared to the Marshall mix design under tropical climate. Onyango and Romanoschi [14] evaluated existing mechanistic models that determine rutting in asphalt mixes by comparing computersimulated permanent deformation to that measured in an accelerated pavement test. Six pavement sections were used with six different asphalt mixes. They concluded that, with some improvements, computer-simulation could be used to predict permanent deformation in asphalt mixes.

Saboo and Kumar [15] examined the change of binder properties on the performance of asphalt mixes. Tests (e.g., Marshall Stability and indirect tensile strength) were used to assess the performance of different modified mixes in fatigue. Results showed that elastomeric modified binder and mixes performed best in fatigue.

Abu Abdo et al. [16] investigated the effects of changing the asphalt mix materials properties on fracture toughness. Results illustrated that mixes with lower asphalt binder contents yielded lower fracture toughness measured by stress intensity factor $\left(K_{\mathrm{IC}}\right)$ and fracture energy. In addition, the study concluded that binders with higher value of lower binder grade number had lower fracture toughness (e.g., mixes with PG 64-22 showed higher values of $K_{\text {IC }}$ and fracture energy than mixes with PG 64-34).
TABLE 1: Details of tested asphalt mixes.

\begin{tabular}{|c|c|c|}
\hline Mix ID & Mix 1 & Mix 2 \\
\hline Binder grade & PG 70-28 & PG 64-34 \\
\hline $\begin{array}{l}\text { Maximum mix specific } \\
\text { gravity, } G_{\mathrm{mm}}\end{array}$ & 2.449 & 2.393 \\
\hline Binder content & $4.9 \%$ & $4.35 \%$ \\
\hline Binder specific gravity, $G_{b}$ & 1.021 & 1.024 \\
\hline $\begin{array}{l}\text { Aggregate effective specific } \\
\text { gravity, } G_{\text {se }}\end{array}$ & 2.639 & 2.568 \\
\hline Sieve size & \multicolumn{2}{|c|}{$\%$ passing } \\
\hline $25 \mathrm{~mm}\left(1^{\prime \prime}\right)$ & $98 \%$ & $100 \%$ \\
\hline $19 \mathrm{~mm}\left(3 / 4^{\prime \prime}\right)$ & $86 \%$ & $100 \%$ \\
\hline $12.5 \mathrm{~mm}\left(1 / 2^{\prime \prime}\right)$ & $73 \%$ & $83 \%$ \\
\hline $9.5 \mathrm{~mm}\left(3 / 8^{\prime \prime}\right)$ & $64 \%$ & $65 \%$ \\
\hline 4.75 mm (\#4) & $41 \%$ & $37 \%$ \\
\hline $2.36 \mathrm{~mm}(\# 8)$ & $27 \%$ & $25 \%$ \\
\hline $1.18 \mathrm{~mm}(\# 16)$ & $18 \%$ & $18 \%$ \\
\hline $600 \mu \mathrm{m}(\# 30)$ & $13 \%$ & $14 \%$ \\
\hline $300 \mu \mathrm{m}(\# 50)$ & $10 \%$ & $11 \%$ \\
\hline $150 \mu \mathrm{m}(\# 100)$ & $5 \%$ & $7 \%$ \\
\hline $75 \mu \mathrm{m}(\# 200)$ & $4.0 \%$ & $4.7 \%$ \\
\hline Pan & $0 \%$ & $0 \%$ \\
\hline
\end{tabular}

Souliman and Eifert [17] examined the effect of adding flexible materials as rubber on the fatigue life of asphalt mixes. Results showed that asphalt mixes with rubber asphalt mixtures would have much longer fatigue life when compared to a conventional mix.

\section{Objectives}

Due to the limitations of current flexible pavement design guides, as discussed in the previous section, this study was conducted to evaluate the effects of different asphalt concrete mix properties on pavement distresses using mechanistic approach. Hence the study focused on

(i) investigating the effects of binder contents on rutting and top down and bottom up cracks,

(ii) evaluating the effects of binder upper grades on rutting and top down and bottom up cracks,

(iii) determining the effects of binder lower grades on rutting and top down and bottom up cracks.

\section{Experimental Program}

3.1. Asphalt Mixes. A wide range of commonly used mixes from the State of Idaho, USA, were selected to construct a mix matrix. The mix matrix consisted of mixes with two different aggregate structures; Mix 1 and Mix 2 (Table 1), three binder contents per aggregate structure (optimum and $\pm 0.5 \%$ from optimum asphalt content), and eight different binder grades (PG). Thus, a total of 14 mixes were evaluated as shown in Table 2. 
TABLE 2: Mix matrix.

\begin{tabular}{lccc}
\hline Mix & PG & Pb\% & Label \\
\hline Mix 1 & $70-28$ & $4.90 \%$ & Mix 1 (Opt) \\
Mix 1 & $70-28$ & $4.50 \%$ & Mix 1 (-0.5\% Pb) \\
Mix 1 & $70-28$ & $5.40 \%$ & Mix 1 (+0.5\% Pb) \\
Mix 1 & $70-22$ & $4.90 \%$ & Mix 1 (70-22) \\
Mix 1 & $70-34$ & $4.90 \%$ & Mix 1 (70-34) \\
Mix 1 & $64-28$ & $4.90 \%$ & Mix 1 (64-28) \\
Mix 1 & $58-28$ & $4.90 \%$ & Mix 1 (58-28) \\
\hline Mix 2 & $64-34$ & $4.35 \%$ & Mix 2 (Opt) \\
Mix 2 & $64-34$ & $3.85 \%$ & Mix 2 (-0.5\% Pb) \\
Mix 2 & $64-34$ & $4.85 \%$ & Mix 2 (+0.5\% Pb) \\
Mix 2 & $64-22$ & $4.35 \%$ & Mix 2 (64-22) \\
Mix 2 & $64-28$ & $4.35 \%$ & Mix 2 (64-28) \\
Mix 2 & $70-34$ & $4.35 \%$ & Mix 2 (70-34) \\
Mix 2 & $58-34$ & $4.35 \%$ & Mix 2 (58-34) \\
\hline
\end{tabular}

\subsection{Lab Tests}

3.2.1. Dynamic Modulus $\left(\left|E^{*}\right|\right)$ Test. Mixes tested by the Dynamic Modulus $\left(\left|E^{*}\right|\right)$ test (AASHTO TP 62-03 [18]) were compacted to achieve $175 \mathrm{~mm}$ height with a total $9 \%$ air voids specimens. Then they were cored and sawed to obtain samples with $100 \mathrm{~mm}$ diameter, $150 \mathrm{~mm}$ height, and $7 \%$ air voids. The test consisted of applying a uniaxial sinusoidal compressive stress to an unconfined test sample and measuring the corresponding strain by 3 LVDTs. Every sample was tested under a series of temperatures 4.4, 21.1, 37.8, and $54.4^{\circ} \mathrm{C}$ and loading frequencies $0.1,1,5,10$, and $25 \mathrm{~Hz}$ at each temperature.

3.2.2. Binder Dynamic Shear Modulus $\left(\left|G^{*}\right|\right)$ Test. The Binder Dynamic Shear Modulus $\left(\left|G^{*}\right|\right)$ was determined using the Dynamic Shear Rheometer (AASHTO T315-06 [19]). Eight binder grades were tested (Table 2); two were neat binders (PG 58-28 and PG 64-22) and the remaining were modified binders (PG 70-22, PG 70-28, PG 70-34, PG 64-28, PG 64-34, and PG 58-34). Tested binders were aged using Rolling Thin Film Oven (RTFO) to simulate the mix aging during mixing and compaction. Tests were conducted under a constant stress of $5000 \mathrm{~Pa}$ at temperature of $21.1^{\circ} \mathrm{C}$.

\section{Methodology}

To achieve the objective of this study, 3D Move Analysis software [20] was used to analyze a flexible pavement structure with different asphalt mix properties. The software was developed by the Asphalt Research Consortium and is available at http://www.arc.unr.edu/Index.html.

3D Move Analysis software was developed based on a continuum-based finite-layer method. This method can determine the effect of different loading conditions (e.g., moving traffic-induced 3D contact normal and shear stress distributions and velocity) and material properties for pavement layers. In addition, 3D Move Analysis incorporates pavement performance models that were based on NCHRP
1-37A models. Many studies on asphalt pavement performance were conducted using 3D Move Analysis software and showed that its results could capture asphalt mixes performance $[17,21-24]$, making it a valuable tool to determine the effects of asphalt mix materials properties on pavement performance.

One of the advantages of using 3D Move Analysis software is allowing users to utilize the frequency sweep test data $\left(\left|E^{*}\right|\right.$ and $\left|G^{*}\right|$ test data) of asphalt mixes in the analysis. It can take into account the viscoelastic materials properties in the analysis, thus making it ideal to model asphalt concrete (AC) layer's reactions to traffic loads and its response as a function of vehicle velocity [20].

A typical 3-layer flexible pavement structure was used in the analysis, consisting of $15 \mathrm{~cm}$ AC layer, $30 \mathrm{~cm}$ untreated base, and subgrade. The design load was a standard dual axle load with 1.9 million repetitions during the design period of 20 years. Then, changes were made to the asphalt concrete layer material properties depending on the lab test results. 3D Move Analysis software allows user to incorporate $\left|E^{*}\right|$ and $\left|G^{*}\right|$ test results into the analysis as Level 1 inputs.

Using $\left|E^{*}\right|$ test data, the software constructs a master curve and determines the damping ratio effects of the evaluated asphalt mixes. Furthermore, $\left|G^{*}\right|$ test results are used to account for the viscous effect of the asphalt binder in the analysis, hence enabling it to determine pavement responses under different loading conditions (i.e., frequencies and temperatures). Then the 3D Move Analysis software utilizes this data to determine the responses (stresses and strains) to predict rutting and top down and bottom up cracks due to loading.

\section{Results and Analysis}

Upon running 3D Move Analysis for the different asphalt mixes (Table 2), rutting depth and top down and bottom up cracking were determined for each mix. In the following subsections, the effects of the changes in asphalt materials properties are discussed.

\subsection{Binder Content Effects}

5.1.1. Rutting of Asphalt Concrete Layer. Rutting depths of asphalt concrete layer were determined for Mix 1 and Mix 2 at the designed optimum and $\pm 0.5 \mathrm{AC} \%$ from optimum binder contents. All mixes were designed to achieve $4 \%$ air voids. As per Superpave Mix Design Method, these mixes should perform best at the optimum asphalt content. As shown in Figure 1, rutting values increased with the increase of asphalt content with lowest rutting depth at $-0.5 \%$ AC from optimum instead of at optimum asphalt content. It is believed that the increase of binder content led to a higher rutting depth due to the reduction of friction between aggregate particles. Furthermore and since Mix 1 was designed with bigger aggregate sizes and a superior binder grade, results showed, as expected, that Mix 1 performed better than Mix 2 with lower rutting depths at different binder contents. 


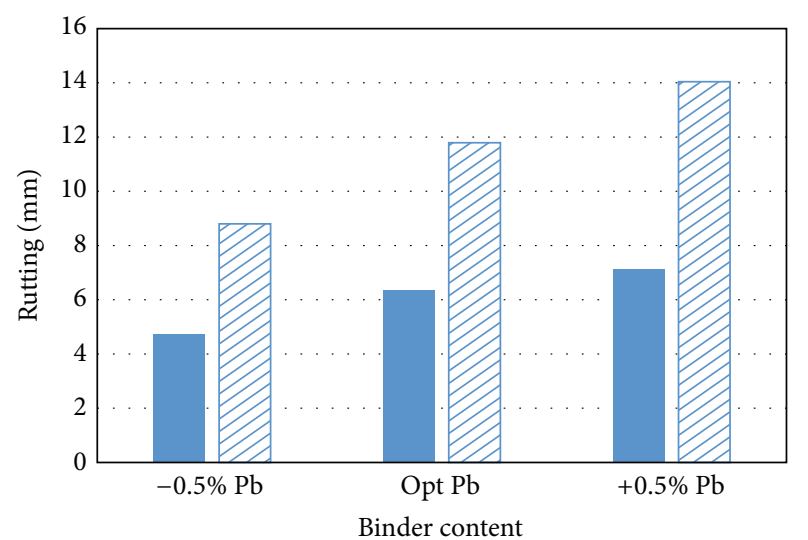

- Mix 1

ㅁ $\operatorname{Mix} 2$

FIGURE 1: Effect of binder content on rutting of asphalt concrete layer.

5.1.2. Cracking of Asphalt Concrete Layer. Bottom up and top down cracks in asphalt concrete layer were determined for Mix 1 and Mix 2 at different asphalt contents, as shown in Figure 2. For bottom up cracking, results indicated that as the percent of asphalt binder increased the percent of bottom up cracks declined (Figure 2(a)). It is believed that, due to the higher binder content, mixes showed higher resistance to tensile strains at the bottom of the asphalt concrete layer. On the other hand and as shown in Figure 2(b), Mix 2 showed higher resistance to top cracks with the increase of binder content. Mix 1 showed more tendency to exhibit more top cracks with the increase of binder content. It could be explained that since Mix 1 and Mix 2 had different aggregate structures, the interaction between the binder and the aggregates led to these results.

\subsection{Binder Grade Effects}

5.2.1. Rutting of Asphalt Concrete Layer. Binder grade effect on rutting of asphalt concrete layer was evaluated by changing the upper and lower numbers of tested binder grades. The upper grade number denotes the highest 7-day temperature a binder can operate. It is mainly considered for permanent deformation (rutting). As for the lower grade number, it denotes the lowest temperature and is mainly considered for thermal cracking. Therefore, it is expected that rutting results of higher grades should be less than a lower grade. Rutting results as presented in Figure 3 showed that for Mix 1 and Mix 2 the higher upper binder grade number (PG 70-28 and PG 70-34) led to lower rutting results when compared to less upper binder grade number (PG 58-28 and PG 58-28).

However, rutting increased with the increase of the lower binder grade number. Figure 4(a) illustrates that Mix 1 with PG 70-22 yielded lower rutting than with PG 70-34 and Mix 2 with PG 64-22 yielded lower rutting than with PG 64-34 (Figure 4(b)). Since 3D Move Analysis software utilizes performance models based on NCHRP 1-37A findings [2], where it utilizes the dynamic modulus test data (master curve) of the evaluated mixes to determine their performance, it is expected that a mix with high stiffness would yield lower rutting. Thus, binders with lower binder grade numbers, which are designed to be softer to avoid cracking at lower temperatures, would exhibit less rutting.

5.2.2. Cracking of Asphalt Concrete Layer. Results of the asphalt concrete layer analysis were inconsistent with the general conception that with higher lower binder grade number (e.g., PG \#\#-34 when compared to PG \#\#-22) lower cracks would be expected in the asphalt concrete layer $[6,7]$. Figure 5 shows that, with the increase of the lower binder grade number for both mixes, higher percent of bottom up cracks would result in the asphalt layer.

As for the top down cracking of the asphalt layer (Figure 6), Mix 1 with PG 70-22 exhibited the lowest value of top down cracking when compared to PG 70-28 and PG 7034. However, Mix 2 performed as expected, with the lowest top down cracking for PG 64-34. Results showed that Mix 1 with PG 70-28 and Mix 2 with PG 64-28 yielded the highest top down cracking results. These results could be explained by the mechanism of how the software determines this distress, where it relies on the master curves constructed by shifting the dynamic modulus test data to determine the stiffness of these mixes at different temperatures and loading frequencies. In addition, these results were consistent with findings of an earlier study [16], where mixes with lower binder grade number yielded lower fracture resistance determined by using lab tests.

\section{Summary and Conclusions}

Based on the results presented, the following observations are made:

(i) Rutting of asphalt concrete layer increased with the increase of asphalt content with the lowest rutting depth at $-0.5 \%$ asphalt content from optimum. It could be concluded that, due to the increase of binder content, friction between aggregate particles (interlocking) is reduced; thus more rutting is expected.

(ii) Results showed that Mix 1 performed better than Mix 2 with lower rutting depths at different binder contents, since Mix 1 was designed with bigger aggregate sizes and higher binder grade.

(iii) Percent of bottom up cracking in the asphalt concrete layer would increase with the reduction of asphalt binder content. The higher binder content would lead to higher tolerance to tensile strains at the bottom of the asphalt concrete layer.

(iv) Mix 2 showed higher resistance to top cracks with the increase of binder content, unlike Mix 1, which showed more affinity to top down cracks with the increase of binder content.

(v) Rutting results of mixes with the higher upper binder grade number were lower when compared to lower upper binder grade number. However, rutting 


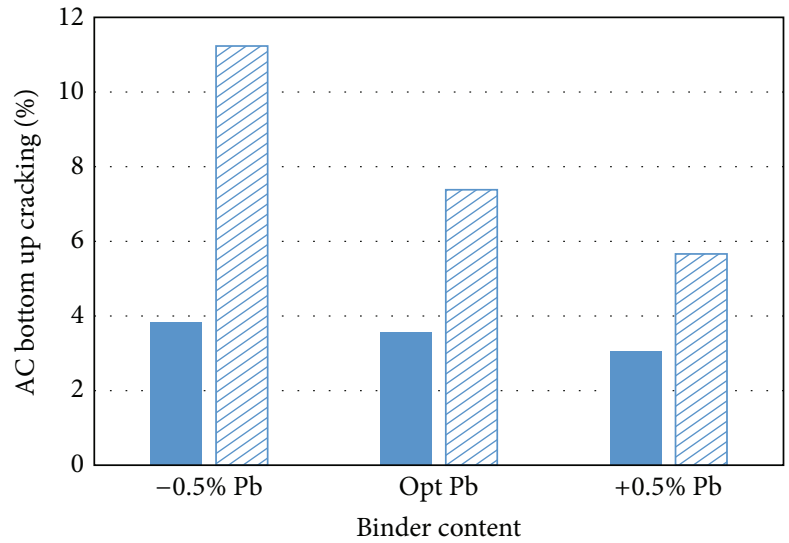

- Mix 1

$\square \operatorname{Mix} 2$

(a) Asphalt concrete layer bottom up cracks

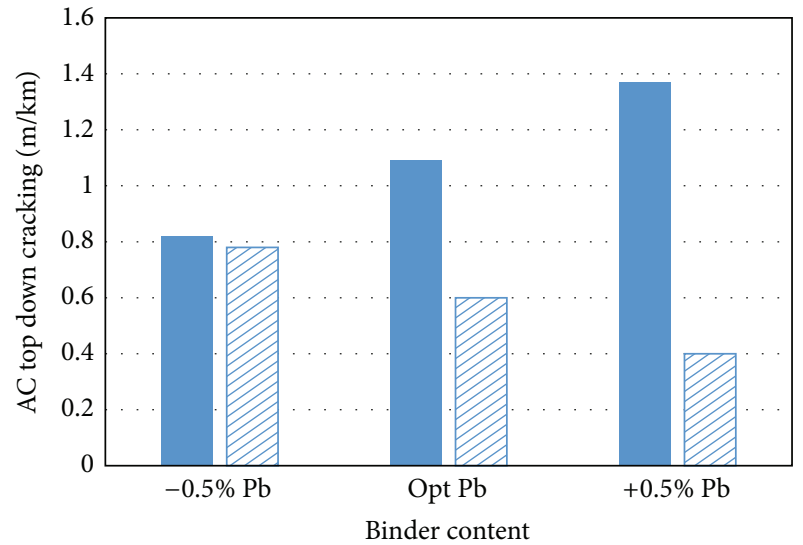

- Mix 1

$\square$ Mix 2

(b) Asphalt concrete layer top down cracks

FIGURE 2: Effect of binder content on cracking of asphalt concrete layer.

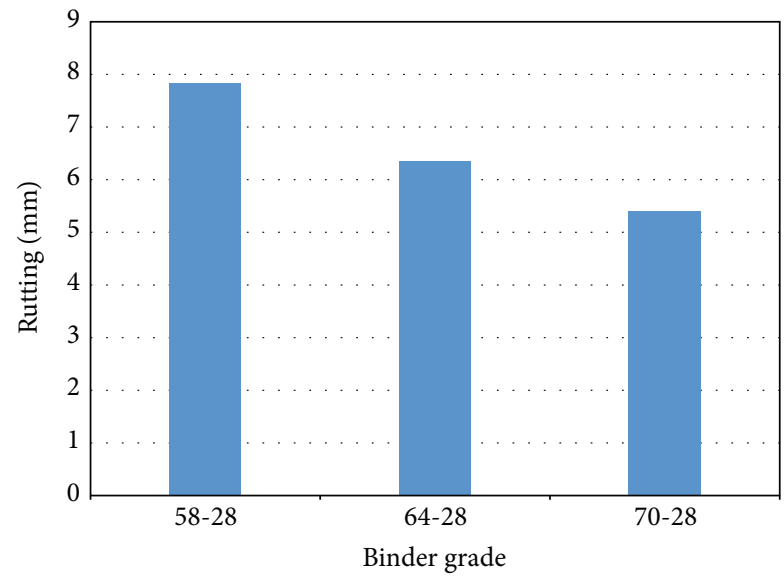

(a) Mix 1

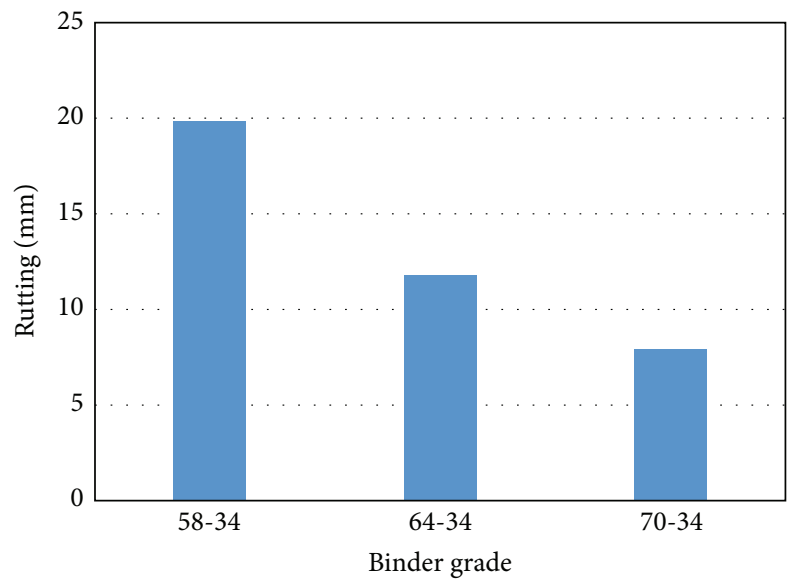

(b) Mix 2

FIGURE 3: Binder upper grade number effect on rutting of asphalt layer.

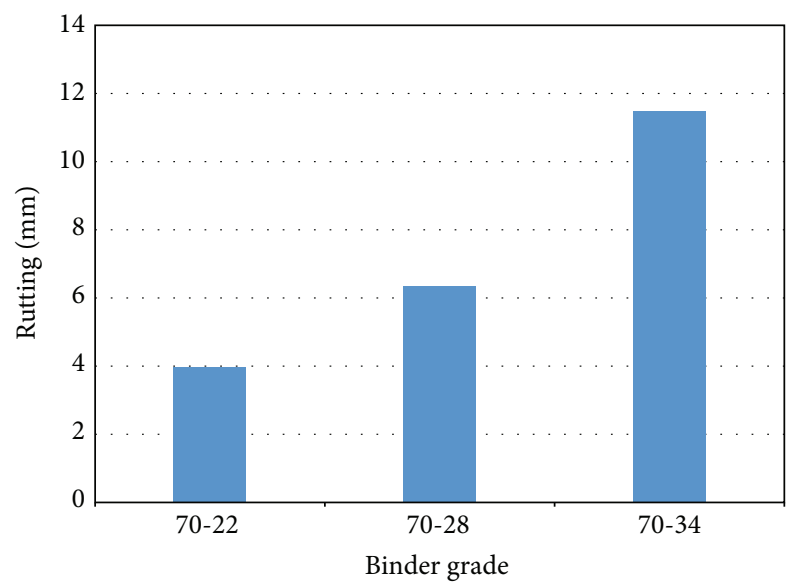

(a) Mix 1

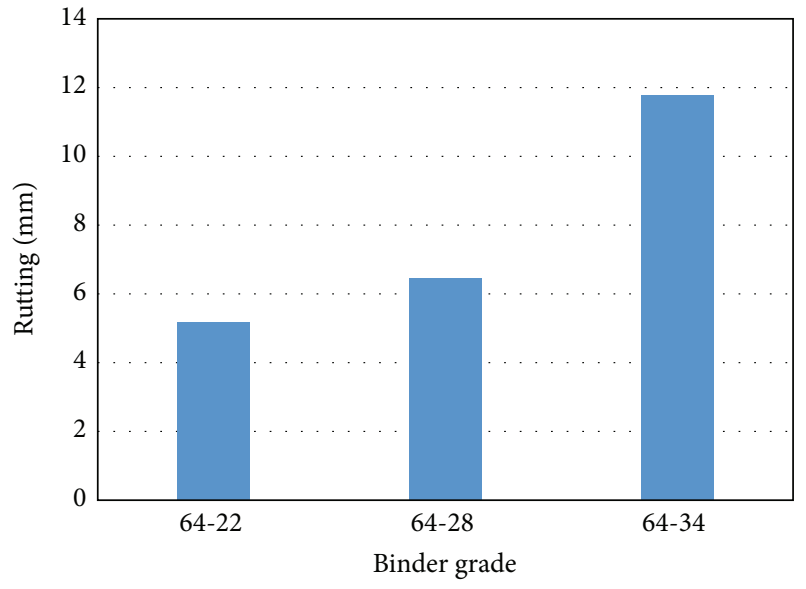

(b) Mix 2

FIGURE 4: Binder lower grade number effect on rutting of asphalt layer. 


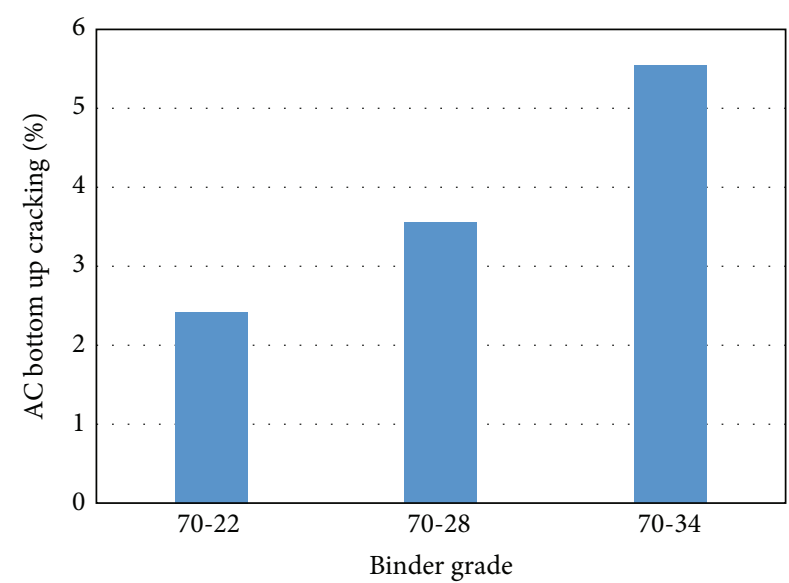

(a) $\operatorname{Mix} 1$

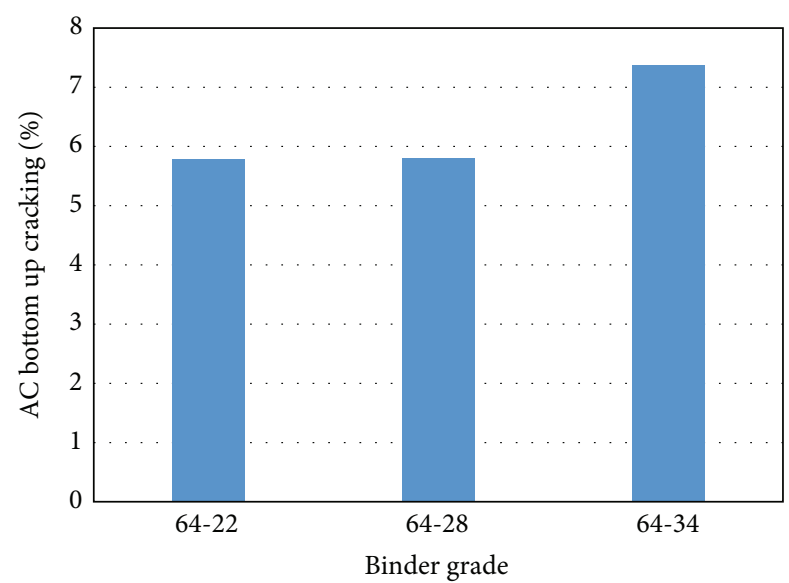

(b) Mix 2

FIGURE 5: Binder lower grade number effect on bottom up cracking of asphalt concrete layer.

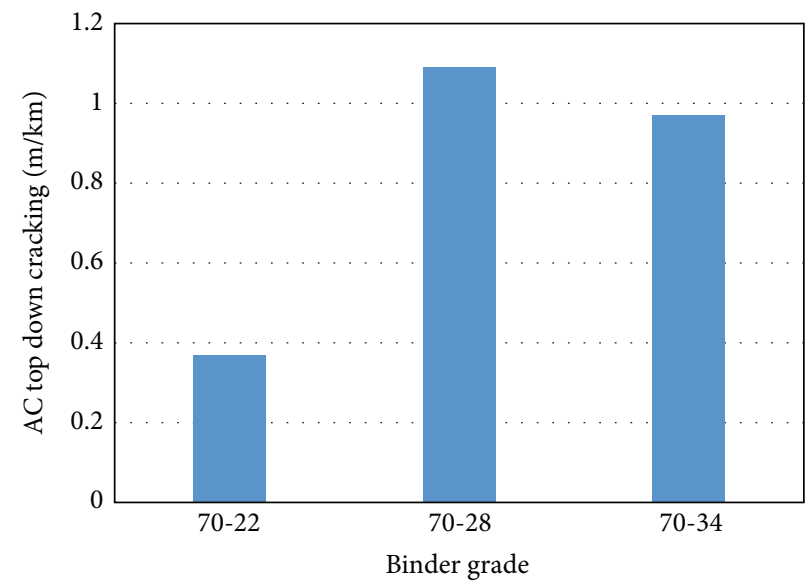

(a) Mix 1

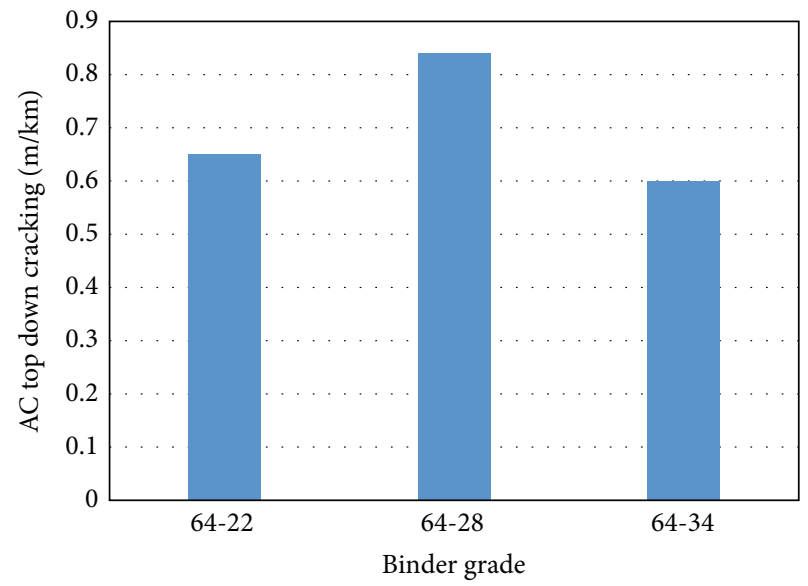

(b) Mix 2

FIGURE 6: Binder lower grade number effect on top down cracking of asphalt concrete layer.

increased with increase of the lower binder grade number.

(vi) Analysis showed that with the increase of the lower binder grade number for both mixes, higher percent of bottom up cracks would result in the asphalt layer. On the other hand, the top down cracking of the asphalt layer for Mix 1 with PG 70-22 exhibited the lowest value of top down cracking when compared to PG 70-28 and PG 70-34. However, Mix 2 with PG 6434 had the lowest top down cracking when compared to PG 64-22 and PG 64-28.

(vii) Overall results showed that using the mechanistic approach to determine the performance of flexible pavements is a better tool than the commonly used methods. It utilizes materials properties and examines their response to different loading conditions and temperatures, which mimics the actual operational conditions.

\section{Competing Interests}

The authors declare that there are no competing interests regarding the publication of this paper.

\section{Acknowledgments}

The authors would like to extend their gratitude to the University of Idaho, USA, and the American University of Ras Al Khaimah, UAE, for the provided support.

\section{References}

[1] Y. H. Huang, Pavement Analysis and Design, Pearson Prentice Hall, Upper Saddle River, NJ, USA, 2004.

[2] "ERES Consultants Division, ARA Inc, Guide for mechanisticempirical design of new and rehabilitated pavement structures," NCHRP Final Report 1-37A, Applied Research Associates, Champaign, Ill, USA, 2004. 
[3] M. I. Darter, J. Mallela, L. Titus-Glover et al., "Changes to the 'mechanistic-empirical pavement design guide' software through version 0.900," NCHRP Research Results Digest No. 308, Transportation Research Board, 2006.

[4] H. L. Von Quintus, M. I. Darter, and J. Mallela, "Manual of practice-interim mechanistic empirical pavement design guide," NCHRP Project 1-40B, Transportation Research Board, Washington, DC, USA, 2007.

[5] J. Mallela, L. T. Glover, M. I. Darter et al., "Guidelines for implementing NCHRP 1-37A M-E design procedures in Ohio: summary of findings, implementation plan, and next steps," Tech. Rep. FHWA/OH-2009/9A, Applied Research Associates, 2009.

[6] R. B. McGennis, S. Shuler, and H. U. Bahia, "Background of superpave asphalt binder test methods," Publication FHWASA-94-069, Federal Highway Administration, Washington, DC, USA, 1994.

[7] R. B. McGennis, R. M. Anderson, T. W. Kennedy, and M. Solaimanian, "Background of superpave asphalt mixture design and analysis," Tech. Rep. FHWA-SA-95-003, Federal Highway Administration, Washington, DC, USA, 1995.

[8] M. A. Elseifi, I. L. Al-Qadi, and P. J. Yoo, "Viscoelastic modeling and field validation of flexible pavements," Journal of Engineering Mechanics, vol. 132, no. 2, pp. 172-178, 2006.

[9] F. M. Bayomy, A. M. Abu Abdo, M. A. Mull, and M. J. Santi, "Evaluation of fracture resistance of hot-mix-asphalt," in Proceedings of the International Conference on Advanced Characterisation of Pavement and Soil Engineering Materials, pp. 1231-1240, Athens, Greece, June 2007.

[10] A. Abu Abdo, F. Bayomy, R. Nielsen, T. Weaver, S. J. Jung, and M. J. Santi, "Prediction of the dynamic modulus of Superpave mixes," in Proceedings of the 8th International Conference on the Bearing Capacity of Roads, Railways and Airfields (BCR2A '09), pp. 305-314, Champaign, Ill, USA, July 2009.

[11] A. M. Abu Abdo, S. J. Jung, and S. I. Baek, "Verification of testing parameters of semi-circle notched beam fatigue test," Asian Journal of Civil Engineering, vol. 14, no. 5, pp. 643-654, 2013.

[12] S. Esfandiarpour, M. A. Ahammed, A. Shalaby, T. Liske, and S. Kass, "Sensitivity of pavement ME design predicted distresses to asphalt materials inputs," in Proceedings of the 2013 Conference and Exhibition of the Transportation Association of CanadaTransportation: Better-Faster-Safer (TAC/ATC '13), Manitoba, Canada, 2013.

[13] J. Ahmad, N. I. Md. Yusoff, M. R. Hainin, M. Y. Abd Rahman, and M. Hossain, "Evaluation on performance characteristics of superpave asphalt mix design under tropical climatic conditions," International Journal of Pavement Research and Technology, vol. 7, no. 5, pp. 331-342, 2014.

[14] M. A. Onyango and S. A. Romanoschi, "Verification of mechanistic prediction models for asphalt mixes," Geotechnical Special Publication 239 GSP, 2014.

[15] N. Saboo and P. Kumar, "Performance characterization of polymer modified asphalt binders and mixes," Advances in Civil Engineering, vol. 2016, Article ID 5938270, 12 pages, 2016.

[16] A. M. Abu Abdo, F. Eckwright, S. J. Jung, F. Bayomy, and R. Nielsen, "Semi-circular notched beam testing procedure for hot mixture asphalt," Proceedings of the Institution of Civil Engineers: Transport, vol. 167, no. 1, pp. 48-58, 2014.

[17] M. I. Souliman and A. Eifert, "Mechanistic and economical characteristics of Asphalt Rubber mixtures," Advances in Civil Engineering, vol. 2016, Article ID 8647801, 6 pages, 2016.
[18] AASHTO, Standard Method of Test for Determining Dynamic Modulus of Hot-Mix Asphalt Concrete Mixtures, AASHTO TP 62-03, American Association of State Highway and Transportation Officials, Washington, DC, USA, 2004.

[19] AASHTO, "Standard method of test for determining the rheological properties of asphalt binder using a Dynamic Shear Rheometer (DSR)," AASHTO T315-06, American Association of State Highway and Transportation Officials, 2006.

[20] ARC, "Report J: pavement response model to dynamic loads 3D move," Quarterly Technical Progress Report, Asphalt Research Consortium, Laramie, Wyo, USA, 2013.

[21] A. L. Priest, D. H. Timm, and W. E. Barrett, "Mechanistic comparison of wide-base single vs. standard dual tire configurations," NCAT Report 05-03, NCAT (National Center for Asphalt Technology), Auburn, Ala, USA, 2005.

[22] R. V. Siddharthan, J. Yao, and P. E. Sebaaly, "Pavement strain from moving dynamic 3D load distribution," Journal of Transportation Engineering, vol. 124, no. 6, pp. 557-566, 1998.

[23] R. V. Siddharthan, N. Krishnamenon, and P. E. Sebaaly, "Pavement response evaluation using finite-layer approach," Transportation Research Record 1709, 2000.

[24] R. V. Siddharthan, N. Krishnamenon, M. El-Mously, and P. E. Sebaaly, "Investigation of tire contact stress distributions on pavement response," Journal of Transportation Engineering, vol. 128, no. 2, pp. 136-144, 2002. 


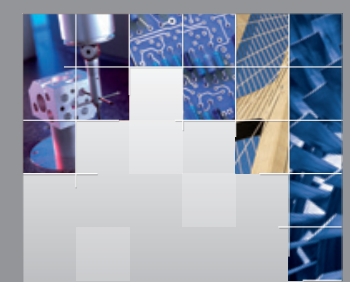

\section{Enfincering}
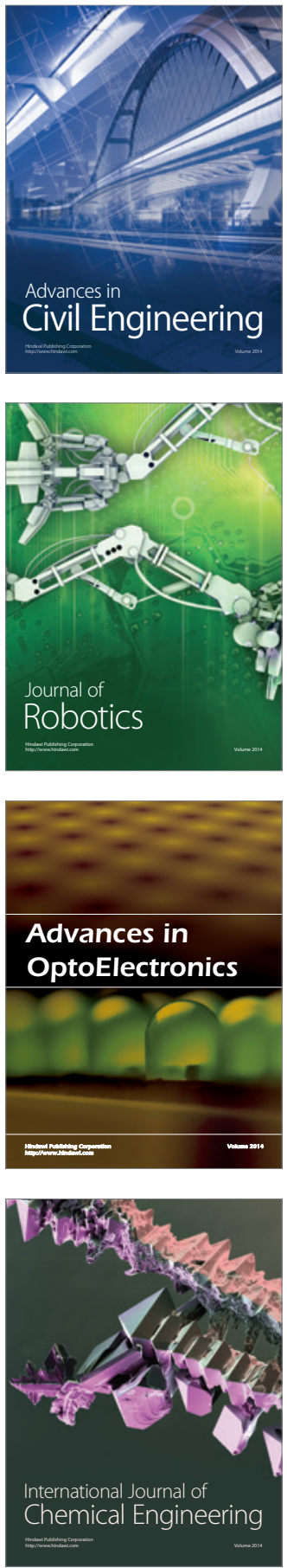

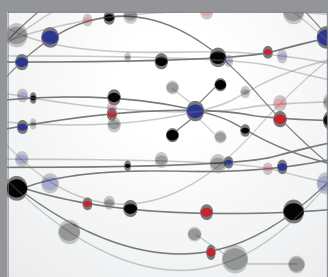

The Scientific World Journal

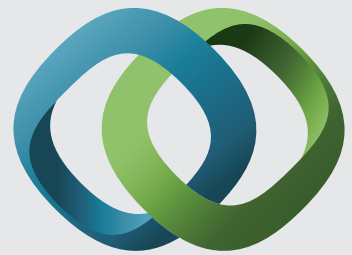

\section{Hindawi}

Submit your manuscripts at

http://www.hindawi.com
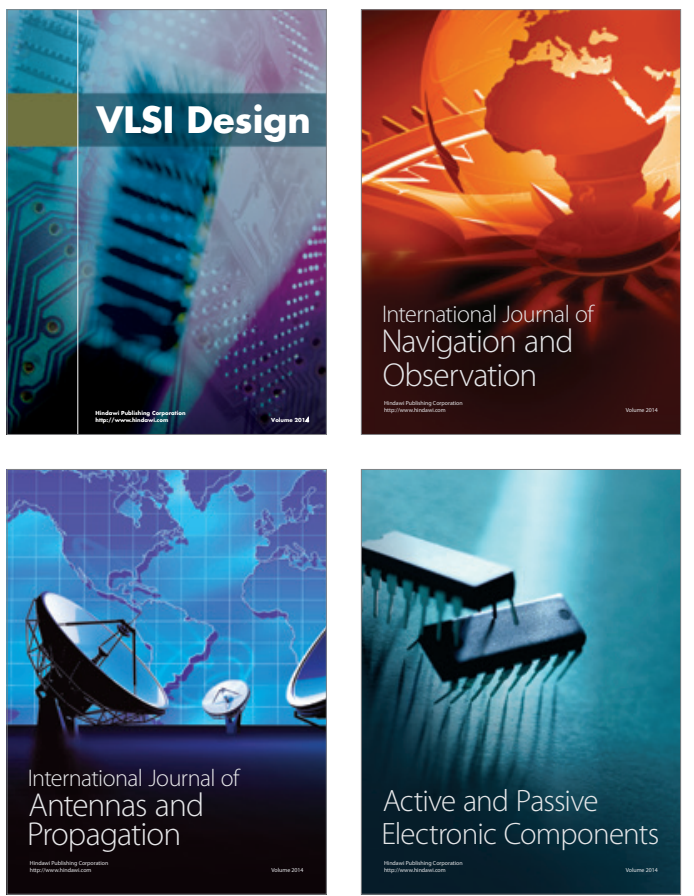
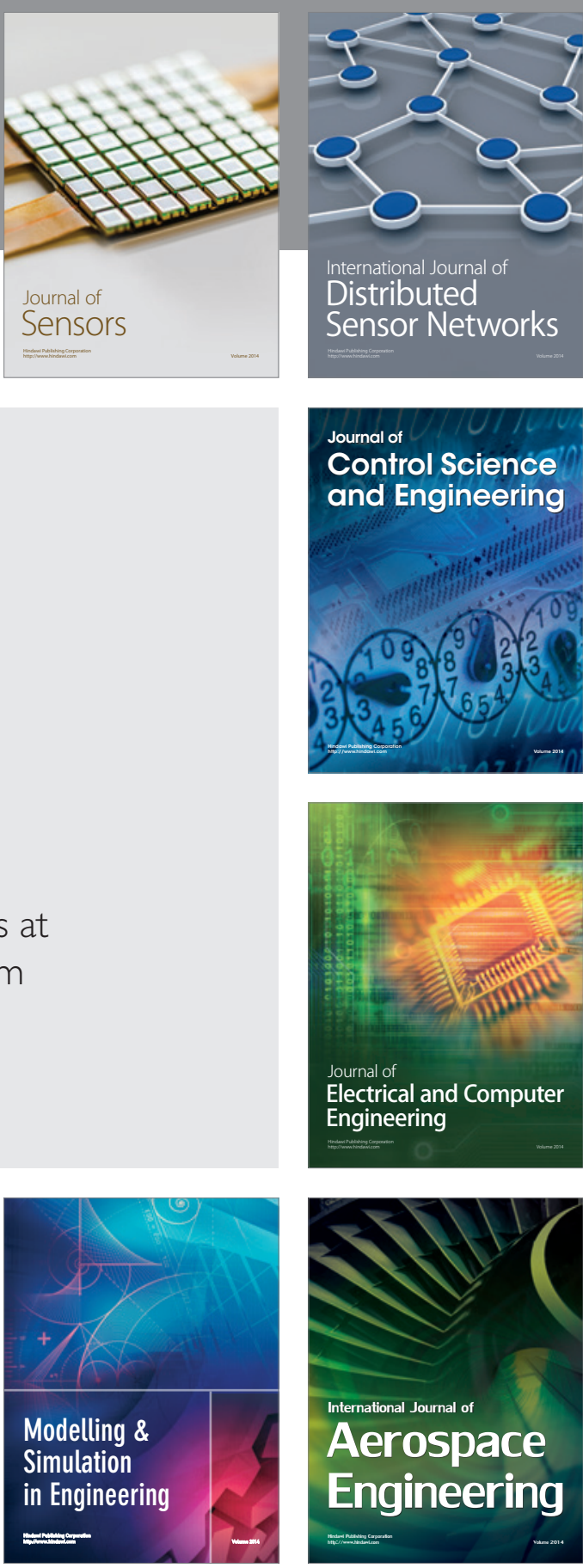

International Journal of

Distributed

Sensor Networks

Journal of

Control Science

and Engineering
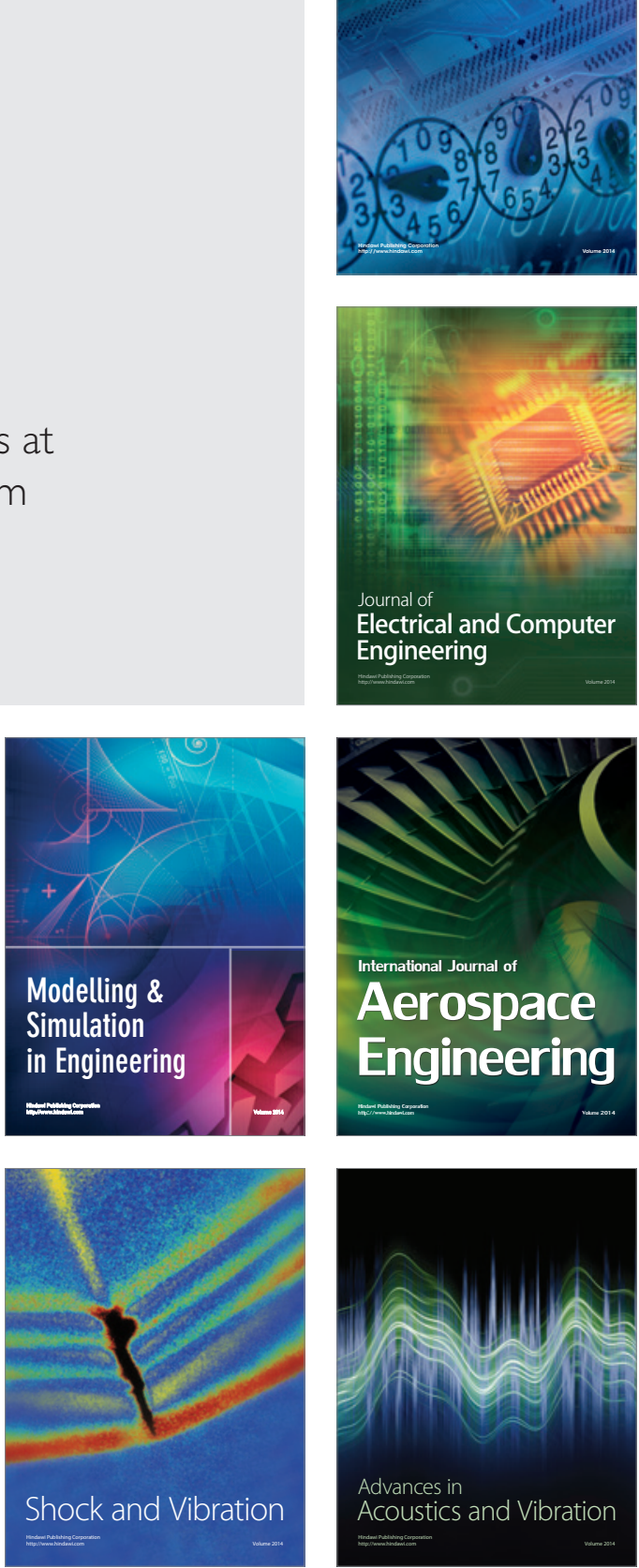